ESPAÇO TEMÁTICO: ESTADO, AUTORITARISMO E LUTA DE CLASSES

\title{
O Estado penal, o sistema prisional e a crise do humanismo
}

\author{
Cibelle Doria da Cunha Bueno ${ }^{1}$ \\ https://orcid.org/0000-0002-6906-6628 \\ ${ }^{1}$ Universidade Estadual do Ceará, Centro de Estudos Sociais Aplicados, Mestrado Acadêmico em Serviço Social Trabalho \\ e Questão Social, Fortaleza, CE, Brasil
}

\section{O Estado penal, o sistema prisional e a crise do humanismo}

Resumo: O presente trabalho busca apresentar a relação entre a constituição do Estado Penal brasileiro, o sistema prisional e a crise do humanismo. O objetivo é aferir a relação entre as categorias supramencionadas no tocante à construção e execução do arcabouço institucional que permeia a política prisional brasileira na contemporaneidade. Nesse sentido, busca-se lançar luzes ao sistema prisional e à naturalização das violações de direitos humanos nesse contexto aferidas, como produto da sociedade instituída a partir da crise do humanismo na contemporaneidade. O estudo em questão foi realizado por meio de pesquisa bibliográfica e documental, tendo nas teorias de Lukács a inspiração para as reflexões aqui apresentadas. Dessa forma, compreende-se que a crise do humanismo, que potencializa o Estado Penal na contemporaneidade, permeou a formação social brasileira e, portanto, demonstra ser característica marcante de nossa sociabilidade, mostrando-se evidente na política prisional atualmente idealizada, planejada e executada no Brasil.

Palavras-chave: Estado Penal. Sistema Prisional. Crise do Humanismo. Contemporaneidade.

\section{The penal state, the prison system and the crisis of humanism}

Abstract: This paper seeks to present the relationship between the constitution of the Brazilian' Penal State, the prison system and the crisis of humanism. The objective is to assess the relationship between the categories mentioned above with regard to the construction and execution of the institutional framework that permeates of Brazilian' prison policy in contemporary times. In this sense, it seeks to shed light on the prison system and the naturalization of human rights violations in the context, as a product of society instituted from the crisis of humanism in the contemporary times. The study in question was carried out through bibliographic and documentary research, taking Lukács' theories as inspiration for the reflection presented here. Thus, it is understood that the crisis of humanism which potentiates the Penal State in contemporary times, permeated Brazilian' social formation and, therefore, demonstrates to be a remarkable characteristic of our sociability showing itself evident in the prison policy currently idealized, planned and executed in Brazil.

Keywords: Criminal State. Prison System. Crisis of Humanism. Contemporary.

Recebido em 30.06.2020. Aprovado em 15.07.2020. Revisado em 05.10.2020.

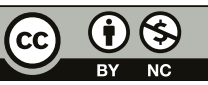

Este é um artigo publicado em acesso aberto (Open Access) sob a licença Creative Commons Attribution NonCommercial, que permite uso, distribuição e reprodução em qualquer meio, sem restrições desde que sem fins comerciais e que o trabalho original seja corretamente citado. 


\section{Introdução}

Aproximando-se de Lukács (2007) verifica-se que a composição teórica do autor, sobretudo quando se refere ao complexo de crises, apresenta características que se mostram latentes no Brasil contemporâneo. Para não tratar de todas as crises citadas pelo autor, apesar de se relacionarem mutuamente - crise da democracia, da razão, do progresso e do humanismo - decide-se, para fins do estudo em tela, abarcar e discutir sobre a crise do humanismo e sua capacidade de se firmar no real, de se concretizar na contemporaneidade e incidir sobre a política prisional em execução no Brasil. Vislumbra-se, desse modo, o humanismo não na visão messiânica e romântica, mas a partir do que se observa na prática em que se vivencia a permanente desconstrução do humanismo a partir de questões criadas pelos próprios seres humanos. Assim, questiona-se: O que fez com que os seres humanos compreendessem que poderiam/podem tratar seres humanos na perspectiva da negação do humanismo, a partir de condutas e políticas anti-humanistas? Por que tratamentos cruéis ou degradantes podem ser aceitos se, e somente se, destinados a determinadas pessoas? O que aconteceu para que os indivíduos se deixassem determinar por suas propriedades e posição social e fizessem disso a motivação de suas concepções de vida, esquecendo-se um dos outros?

Dessa forma, considera-se imprescindível, para a compreensão da crise do humanismo e seus rebatimentos na contemporaneidade, a análise do termo humanismo e, sobretudo, a crise deste na contemporaneidade, a partir do olhar sobre categorias cruciais como Estado e pena de prisão. Considerar, para tanto, o Estado hegemônico que se vivencia agora, agregando elementos históricos, políticos e sociais para a análise do mesmo, em constante interação com as expressões da realidade que povoam os noticiários, com os quais tem-se contato diário, e que indicam o crescente número de homicídios de pretos e pretas jovens, periféricos e pobres. Aliado ao contexto narrado evidencia-se um processo sistemático, de cunho político, que sustenta a retração de direitos sociais como premissa para o desenvolvimento econômico brasileiro, associado à precarização das condições de trabalho e vida da classe trabalhadora, legitimado por meio dos discursos de ódio que são aplaudidos em campanha eleitoral. Diante de tudo isso, o clamor pela prisão é produto incontestável do contexto contemporâneo, sendo imprescindível que alternativas sejam pensadas como possibilidades de reversão dessa crise que só tende a se agudizar.

Dessa forma, o presente trabalho tem por objetivo investigar a relação existente entre o Estado penal brasileiro contemporâneo, o sistema prisional e a crise do humanismo, em tempos em que se vê, bem próximo e cada vez mais fortalecido, o ideário em torno do autoritarismo e das ideias de extrema-direita. Por meio de uma revisão de literatura das principais concepções ideológicas traçadas por meio da criminologia crítica pretendese traçar as características e peculiaridades do que a literatura tem denominado Estado penal no Brasil, suas repercussões na sociabilidade do Brasil contemporâneo, assim como o que corresponderia o humanismo e sua crise contemporânea que influi nas práticas punitivas brasileiras, sobretudo no sistema prisional da atualidade.

\section{Estado Penal brasileiro contemporâneo}

As reflexões acerca do Estado penal, a serem tecidas neste trabalho, consideram, sim, o processo de agigantamento das práticas repressivas brasileiras no contexto do capital, isto é, predominantemente contemporâneo e influenciado pelo neoliberalismo. Contudo, não se restringirão à análise a partir desse contexto histórico específico, visto que o Estado Penal, para a análise a ser desenvolvida neste estudo, é considerado produto de fatores, consequência de acúmulos históricos e sociais, constituindo-se, portanto, enquanto fenômeno multidimensional e, dessa forma, dotado de características socio-históricas agregadas, para se conformar, hoje, como Estado penal. Nessa perspectiva consideramos que a construção do Estado penal, enquanto termo, mas também ideologia e hegemonia implementadas pelo Estado brasileiro para pensar ações coletivas, políticas públicas de governo e Estado e, para de alguma forma, atuar em busca de legitimidade social, parte da formação socio-histórica do País e possui forte relação com a mesma.

O Estado brasileiro, assim como os demais Estados nacionais absorveu os reflexos dos modelos de Estado engendrados em nossa sociedade. Atravessamos o modelo de Estado Absolutista a partir das imposições econômicas, políticas, culturais, comportamentais e sociais da Colônia Portuguesa, de um Estado cujas ações se centravam na figura do Rei, cujo Estado e o poder personificava. A partir da dissociação entre a persona 
do Rei e o Estado, isto é, no momento em que este ganha sua própria personalidade, ingressamos em um modelo de Estado Liberal, idealizado e fomentado a partir da Revolução Francesa e dos ditames liberais que apregoavam a livre iniciativa e ao mercado como poder regulador das relações sociais e econômicas. $\mathrm{O}$ Estado liberal tinha como premissa a liberdade individual e a evolução das técnicas de poder, em que estas assumiriam a função legal e não mais pessoal, conforme se configuravam no modelo de Estado Absolutista (BARBOSA; COELHO, 2017).

No Brasil, o Estado liberal, como os demais modelos de Estado, foi imposto como motivação para a Abolição da Escravatura, em 1888, e incitou o processo de industrialização abrupta e sem planejamento, sofrido pelo país. As consequências desse processo de formação socio-histórica, no tocante ao processo de urbanização desordenada, êxodo rural e segregação de um contingente social específico, que se encontra nos morros, comunidades e aglomerados de todo país, pode ser aferida até os dias atuais. Conforme pondera Jessé de Souza (2017), constitui a dita ralé brasileira ${ }^{1}$.

O modelo de Estado social, vivenciado no momento da crise do Estado Liberal, implementou políticas de caráter paternalista e de cunho social, destinada à classe trabalhadora e aos vulneráveis sociais, consolidando, nesse contexto, o ideário social necessário à reprodução do sistema econômico hegemônico, o capitalismo (SILVA, 2005). Um desdobramento do Estado social, vivenciado exclusivamente pelos países europeus, sobretudo no pós-guerra e pelos países devastados pela mesma, instituiu as políticas sociais como maneira de refazimento das condições de vida da classe trabalhadora, severamente afetada pelas mazelas sociais consequentes da guerra. É nesse contexto que foi vivenciado nos países europeus e nos países norte-americanos o classificado Welfare State ${ }^{2}$, ou Estado de Bem-estar social, em que as ações estatais potencializaram a garantia dos direitos sociais, indicando-os como direitos fundamentais (BARBOSA; COELHO, 2017).

No Brasil vivencia-se o Estado social de forma incipiente, de maneira formal, no papel, muito mais do que na realidade. A Constituição de 1934 trouxe os direitos sociais como direitos fundamentais e iniciativas de políticas sociais vinculadas ao Estado foram forjadas, mesmo que com forte influência e de execução da Igreja Católica e entidades filantrópicas. As ações paternalistas e motivadas pela necessidade de legitimidade do governo foram o foco do Estado social brasileiro instituído em 1930. É por este motivo que, embora o Brasil tenha implementado políticas sociais, estas ainda estavam intrinsecamente relacionadas à benemerência e ao assistencialismo, motivo pelo qual não se pode falar em um Estado de Bem-estar social brasileiro, regido pelo pleno emprego e políticas sociais fortes, mas tão somente de um Estado social paternalista e em busca de legitimidade social. Tal cenário deflagra a fragilidade com que os direitos sociais entraram no contexto socio-histórico brasileiro e possibilita a reflexão em torno da promoção dos mesmos, enquanto direito de fato, corresponderem, ainda, a um desafio atual e recorrente na sociedade brasileira:

A concepção de exclusão social como perda de uma conquista [...] pressupõe a anterior universalidade da cidadania. No caso brasileiro, este patamar de universalidade da cidadania não foi ainda consagrado nem na sociedade, nem no Estado [...] A cultura patrimonial predominante não incorpora padrões básicos e universais de cidadania. A inclusão dos que menos tem é circunstancial, casuística, meritocrática e seletiva. Este tipo de sociedade não incorpora uma cobertura universal dos riscos sociais (SPOSATI, 1999, p. 71).

O Estado Neoliberal, no qual se localiza o expressivo termo do Estado penal é fomentado após a crise do Estado de Bem-estar social no mundo. No Brasil, este Estado nasce, enquanto termo e hegemonia facilmente identificável e institucionalizada, a partir de imposições político-internacionais para inserção do Brasil no processo de mundialização do capitalismo. A transição democrática e o acirramento do neoliberalismo, ocorridos no contexto brasileiro, sobretudo após o Consenso de Washington ${ }^{3}$, nas décadas de 1980 e 1990, proporcionaram a reordenação das ações do Estado brasileiro a fim de intensificar a acumulação do capital e para que este integrasse as economias nacionais à lógica de acumulação globalizada. Nesse mesmo período, o Movimento de Lei e Ordem dos Estados Unidos, lá desenvolvido na década de 1970, chega ao Brasil, já década de 1990, com uma de suas ramificações: O Tolerância Zero. A premissa do Movimento seria distinguir os cidadãos de bem ${ }^{4}$, merecedores da proteção legal, dos ditos bandidos, aos quais deveria se aplicar com severidade a lei penal. Nesse sentido, a política de Tolerância Zero buscava arrefecer a insegurança das classes altas e médias brasileiras, sendo intolerante a crimes de menor potencial ofensivo, mas que de alguma forma incomodavam a elite em questão. Assim, o objetivo se assentava na "[...] retirada da sociedade dos ditos 
"excrementos humanos" [...] recriminando severamente delitos menores tais como embriaguez, a jogatina, a mendicância [...]" (ARAGÃO, 2010, p. 2).

O Estado brasileiro, em questão, efetiva a política prisional, por este engendrada e formatada, como demonstração de seus esforços para incidir sobre a insegurança social e os altos índices de criminalidade e violência, características irrefutáveis da sociedade brasileira contemporânea.

\section{Estado e pena}

A pena privativa de liberdade remonta os tempos de Cristo, e especialmente no Brasil, concretiza-se desde o Brasil Colônia, obtendo, a partir de então, as mais variadas funções. Inicialmente, tinha como premissa ser o depositário de pessoas que eram classificadas como sujeitos suspeitos pela Justiça ou aguardavam a sentença oficial (AGUIRRE, 2009). Posteriormente, já com a aproximação das diretivas capitalistas, a prisão era considerada um espaço em que os apenados deveriam se tornar cidadãos dignos por meio da prática laboriosa. Nada que se assustar com a similaridade atual, em que o trabalho é visto como prática central para a dita recuperação dos delinquentes.

A fim de elucidar o desenvolvimento e formatação do sistema e método punitivo instituído nos diferentes momentos históricos, sociais e econômicos, compartilhamos o Quadro 1, em que sistematizamos as principais características de cada período, considerando que em outros momentos tais modelos de Estado e métodos punitivos já foram abordados.

\section{Quadro 1 - Estado e Pena}

\begin{tabular}{|c|c|c|c|c|}
\hline Período Histórico & Baixa Idade Média & Alta Idade Média & Idade Média & Idade Moderna \\
\hline $\begin{array}{l}\text { Método punitivo } \\
\text { predominante }\end{array}$ & Indenização e Fiança & $\begin{array}{l}\text { Prisão e castigos } \\
\text { corporais }\end{array}$ & $\begin{array}{l}\text { Prisão e castigos } \\
\text { corporais }\end{array}$ & $\begin{array}{l}\text { Fianças/Prisão e } \\
\text { castigos corporais }\end{array}$ \\
\hline Sistema de punição & Pena pecuniária & Penais corporais & Penais corporais & $\begin{array}{l}\text { Penais imputadas a } \\
\text { partir da classe social } \\
\text { do condenado }\end{array}$ \\
\hline $\begin{array}{l}\text { Modo de produção } \\
\text { vigente }\end{array}$ & Feudal & Feudal & $\begin{array}{l}\text { Transição Feudalismo/ } \\
\text { Capitalismo }\end{array}$ & Capitalismo \\
\hline $\begin{array}{l}\text { Objetivo do Direito } \\
\text { Penal/Criminal }\end{array}$ & $\begin{array}{l}\text { Preservação da } \\
\text { hierarquia social }\end{array}$ & & $\begin{array}{l}\text { Preservação do } \\
\text { desenvolvimento } \\
\text { econômico }\end{array}$ & $\begin{array}{l}\text { Avaliação de } \\
\text { considerações sociais } \\
\text { e morais para definir a } \\
\text { intensidade da lei a ser } \\
\text { aplicada }\end{array}$ \\
\hline
\end{tabular}

Fonte: Elaborado pela autora com base nos escritos de Rusche e Kirchheimer (2019).

Assim, compreendemos que, de certa forma e por razões díspares, a prisão sempre esteve presente enquanto método punitivo, durante os diversos períodos históricos, conforme demonstra o Quadro 1. Nessa perspectiva, o que é a prisão se não "apenas uma expressão da instituição maior e mais abrangente chamada de punição" (GENELHÚ; SCHEERER, 2017, p. 60). Em razão de tais relações estabelecidas entre a pena, o Estado e o processo de definição da sociabilidade humana e da culpabilidade ${ }^{5}$, abordaremos o processo de consolidação de tal relação, apresentando, para tanto, as teorias da pena como processo social de definição de interesses, anseios dos entes Estatais e da sociedade, no tocante à instituição e validação dos sujeitos classificados como culpados e não culpados diante da forma de organização e sociabilidade apresentada em cada momento histórico.

A pena, sua necessidade e função, conforma discussões que pretendiam definir teorias que contivessem, de maneira satisfatória, a finalidade da pena e sua dita, 'missão', no contexto público. Tais questões visavam 
solidificar a ideia de que ao Estado cabia a responsabilidade de punir, desde que este obtivesse o respaldo racional e científico para tal (BITENCOURT, 2004), considerando que outrora, a pena era cumprida no ambiente privado, no âmbito do particular.

Teorias relacionadas à função da pena foram sendo construídas. No Estado Absolutista, a pena se assentava na função de imputar o castigo que se baseava na necessidade de expiação do mal, considerado o pecado. A teoria em questão, considerada Teoria Absolutista ou Retributiva da pena, presume o livre-arbítrio dos homens, ou a capacidade destes para distinguir entre o justo e injusto - argumento este, passível de contestação, como veremos posteriormente. Nesse sentido, a pena possui o caráter de retribuir o mal praticado pelo delinquente com a prática institucionalizada de outro mal, a própria pena, que teria, portanto, o fim em si mesma. "Com a aplicação da pena consegue-se a realização da justiça, que exige, diante do mal causado, um castigo que compense o mal e retribua, ao mesmo tempo o seu autor" (BITENCOURT, 2004, p. 107).

O fundamento ideológico das teorias absolutas da pena baseia-se no reconhecimento do Estado como guardião da justiça terrena e como conjunto de ideias morais, na fé, na capacidade do homem para se autodeterminar e na ideia de que a missão do Estado frente aos cidadãos deve limitar-se à proteção da liberdade individual. Nas teorias absolutas coexistem, portanto, ideias liberais, individualistas e idealistas. (JESCHECK, 1981, p. 96).

Considerando a relação entre a pena e o Estado, sabemos que o desenvolvimento do ideário liberal e a implementação do Estado liberal traz consigo a necessidade da pena que cumprisse o papel de realizar e/ou contribuir na realização dos objetivos capitalistas.

Assim, com o desenvolvimento das sociedades, novas conformações dos Estados, as ideias iluministas que desejavam liberar, totalmente, a pena das considerações metafísicas e metassociais ${ }^{6}$, abordadas nas teorias retributivas, foram sendo deflagradas. Dessa forma, amparando-se nos dizeres de Sêneca, que considerava que "nenhuma pessoa responsável castiga pelo pecado cometido, mas sim para que não volte a pecar", foram construídas as teorias preventivas gerais da pena, cujo ponto principal era "inibir, tanto quanto possível, a prática de novos delitos [...] a partir da ideia da intimidação ou utilização do medo e a ponderação da racionalidade do homem" (BITENCOURT, 2004, p.124).

Considerando vários aspectos que apontavam a fragilidade das teorias retributivas e teorias preventivas gerais, as teorias de prevenção especial foram sendo concebidas, considerando ser a finalidade da pena evitar delitos posteriores, mas que a prevenção a ser realizada deveria se concentrar nos delinquentes. Desse modo, a prevenção se daria a partir da adoção de medidas que considerassem a "ressocialização e reeducação do delinquente, à intimidação daqueles que não necessitavam se ressocializar e a neutralização dos considerados incorrigíveis" (ROSAL; VIVES, 1999, p. 688). Contudo, tal teoria desconsidera que:

Ninguém em sã consciência ignora que não há nada mais distante da ressocialização do que a prisão. Basta destacar os novos hábitos que o recluso deve adquirir ao ingressar na prisão, tais como vestimenta, horários para todas as atividades pessoais, formas determinadas de andar pelos pátios, a observação do "código do preso": em resumo, a assimilação de uma nova cultura, a cultura prisional. (MUÑOZ CONDE, 1979, p. 145).

Consideramos, dessa maneira, que as teorias se inter-relacionam e se retroalimentam em vários aspectos, considerando serem as teorias modernas, reconfigurações e/ou releituras das teorias absolutas e relativas.

Observamos, assim, que o Sistema de Justiça brasileiro se construiu e consolidou o arcabouço que conforma o Direito penal a partir das orientações das teorias acima elucidadas. Sendo assim, acumula em suas normativas e interpretações aspectos que evocam as teorias modernas, evoluções encontradas a partir da criminologia crítica - que embasa toda a discussão desse estudo - e a implementação do garantismo penal, como fruto dessa corrente teórica; apesar de obter introjetado na representação social de sua sociedade, aspectos, sobremaneira, atrelados às raízes das teorias absolutas e relativas da pena, de origem conservadora e desprovida de conexão com a realidade social vivenciada.

Identificamos, dessa forma, certo distanciamento entre as premissas orientadoras das teorias das penas de conteúdo moderno, a partir da ressignificação das teorias de base - absolutas e relativas - embasadas nos princípios do Estado Democrático de Direito e nos primados dos direitos humanos com o que de fato ocorre 
no dia a dia das penitenciárias e no Sistema de Justiça brasileiro ${ }^{7}$. E ao falar de Estado, enfatizamos o Estado brasileiro considerando as condições peculiares das prisões no país que além de imputarem aos apenados condições desumanas de sobrevivência, apresentam esse modelo punitivo como a forma ordinária e eficaz de punição dos classificados delinquentes. O encarceramento em massa ${ }^{8}$ se coloca hoje como uma necessidade essencial à reprodução do modelo econômico vigente, e exatamente por isso, se mostra extremamente seletivo, fomentador de segregação e desigualdade. Assim, "a arbitrariedade e a seletividade da prisão demonstram que o seu conceito não é jurídico, mas sim político e econômico" (MENESES, 1996, p. 127).

Toda prisão é uma prisão político-econômica, e promove aprisionamentos político-econômicos, porém, não no sentido de aprisionar agentes políticos e pessoas endinheiradas. Estas têm poder de indignação e de inconformação suficiente para impedir que elas sejam rotuladas como inimigas e principalmente como inimigas convenientes. O poder configurador político-econômico da prisão significa que ela age de acordo com a discricionariedade. Fazendo e desfazendo, prendendo e soltando aqueles que sejam mais adequados e úteis. Se a prisão de uma pessoa não for interessante, ou se ela exigir custos muito altos, sobretudo políticos, renuncia-se à privação da sua liberdade, que fica adiada para depois ou para nunca mais (GENELHÚ et al., 2017, p. 255).

Nesse aspecto, convém ressaltar que, na maioria das situações, o que se percebe é a criminalização como processo regular e classificatório das populações marginais, pois, de acordo com Nilo Batista et al. (2003, p. 18), "criminalidade não existe, o que existe é criminalização. Este é verdadeiro, porque a criminalidade seria um somatório de todas as infrações, o que não existe". Segundo o mesmo autor "a criminalização é uma construção humana feita seletivamente", sendo, portanto, "um processo político de emprego de poder punitivo".

Não é em vão, que até os dias atuais, o encarceramento tem por premissa perpetrar violações de direitos humanos às pessoas apenadas e, mais ainda, é restritamente aplicável a um contingente social específico que tem gênero, cor, faixa etária, nível de escolaridade e territorialização bem definidas.

[...] o sistema de Justiça atua de modo indiscriminado contra jovens pobres da periferia, sendo a aceitação de parcas provas para sua condenação ou seu aprisionamento provisório a demonstração clara de que o poder punitivo não se intimida frente à possibilidade de produção de injustiças, especialmente quando está direcionado àqueles que preenchem o estereótipo que povoa os cárceres do país. (SAMPAIO, 2013 apud PIMENTA, 2018, p. 131).

Fica, pois, evidente, que por trás da máquina de moer gente ${ }^{9}$ existem determinantes estruturais, ideológicos envolvidos responsáveis por promover a construção de um inimigo do Estado, o qual deve sofrer ações incisivas deste no sentido de contê-lo, puni-lo e repreendê-lo, por meio do encarceramento e da destituição de sua condição de ser humano dentro dos espaços de tutela do Estado. Nessa perspectiva, o sistema penal:

[...] é necessário como instrumento de controle social penal da massa de excluídos, produzidos, justamente pelo projeto político que traz a reboque a necessidade de minar os campos por onde se movimentam os excluídos, para que a cada passo mais afoito, exploda-lhes um delito aos pés. Ademais, a poderosa indústria para controle do crime não pode prescindir de uma criminalidade que, ao menos, mantenha os níveis de recursos no patamar atual (MAZZILLI NETO, 2007, p.40).

Assim, a pena/castigo aplicadas a este contingente populacional, sobretudo a forma de execução da pena privativa de liberdade, baseada na ideia do direito do inimigo ${ }^{10}$ de Jakobs, não é escolhida sem intencionalidade ou por motivos desconexos do contexto social, como não é em vão que está se reproduza de maneira tão contundente no cenário contemporâneo brasileiro.

No dizer de Zaffaroni, as racionalizações da doutrina penal para omitir e ocultar a incorporação da categoria do inimigo no direito penal são concessões do Estado Liberal ao Estado Absolutista que ferem o modelo de um Estado de Direito preocupado em suplantar as violências históricas e reais das estruturas jurídicas e econômicas. (XAVIER, 2020, p. 22).

Conforme dados obtidos na análise do Infopen 2019 (BRASIL, 2019), cujos dados foram coletados no período entre junho e dezembro de 2019, temos uma massa carcerária composta por mais de 750 mil vidas, 
das quais a maioria é composta por pessoas negras (66\%), que não possuem sequer o ensino fundamental completo $(57,6 \%)$, sendo a maioria composta por homens jovens (49\%), cuja faixa etária encontra-se entre 18 e 29 anos $^{11}$. Observamos, portanto, uma juventude, preta e pobre encarcerada, segregada e maltratada pelo Estado com toda a aceitação popular, que além de se mostrar condescendente com a prisão enquanto modelo punitivo ordinário, clama por sua efetivação relacionando-a à concretização da tão conclamada justiça.

\section{Crise do Humanismo e sistema prisional brasileiro}

Observamos, nesse sentido, no contexto de crise do capitalismo o acirramento das formas de barbárie e o condicionamento da sociedade ao estabelecimento de uma sociabilidade baseada na guerra permanente. Todos contra todos, é o lema! Ou salve-se quem puder! As situações de barbárie e crueldade, fruto do próprio sistema econômico capitalista, e necessário à reprodução deste, podem ser deflagradas a partir da observação acerca da sociabilidade contemporânea que tem promovido o acirramento do individualismo, da competição, propagação do discurso de ódio e a necessidade de afirmação constante da diversidade, introjeção do discurso da meritocracia como regra e, sobretudo, o fortalecimento da própria política prisional, fonte de violações de direitos humanos incomensuráveis e, pior, institucionalizadas e de conhecimento de todos desde seus primórdios.

Para Lukács (2007, p.45), autor que aborda a crise do humanismo: "O humanismo, em sua gênese e por sua própria essência, é um conhecimento do homem voltado para a defesa da sua dignidade e dos seus direitos". No que tange à conquista da história humana, admite-se o humanismo como prática do reconhecimento do gênero humano no outro, na dignidade humana como premissa irrefutável e na percepção de que as condições sociais devem possibilitar a existência digna de todos os homens, sustentando assim, a humanidade.

Nesse cenário, a luta pela dignidade dos indivíduos e o humanismo propriamente dito representam uma abstração, um utopismo, já que dependem da correlação de forças sociais que se encontram, fortemente ativas contra as premissas que constituem o humanismo.

O humanismo perde seu fundamento nas ciências concretas do homem. A luta pela dignidade e pelos direitos humanos vê-se compelida gradualmente a assumir uma posição defensiva, ideologicamente coagulada em abstrações que conduzem cada vez mais - dada a sua alienação em face da realidade social concreta - a um pálido utopismo (LUKÁCS, 2007, p. 45).

Segundo Lukács, a crise do humanismo considera a ausência voraz do humanismo e de suas práticas reais pelas instituições. Exatamente por isso consideramos que a crise do humanismo, no contexto brasileiro, se faz presente no decorrer de nossa formação socio-histórica, visto projetarmos um país sob as bases de um projeto colonizador racista, elitista e sem o sentido de pertença do povo brasileiro. A crise do humanismo, segundo Lukács, é de fácil reconhecimento se lembrarmos a durabilidade das ideias nazistas na Alemanha, que se implementaram durante doze anos. Assim, a permanência, valorização e clamor pelo sistema prisional brasileiro, com violações de direitos humanos institucionalizadas e crescentes, constituem bases para que reforcemos a crise do humanismo no Brasil contemporâneo, que se fortalece e se consolida a passos largos. Esta, por sua vez, faz parte de um todo crucial à sua implementação, sustentada sob a égide do Estado, consolidado a partir dos ditames neoliberais e a desumanização própria do sistema hegemônico, que visa escolher os merecedores da humanização ${ }^{12}$.

A crise do humanismo, conforme propõe Lukács trata, portanto, da descrença da dignidade humana como premissa fundamental e como base de sustentação de uma sociedade democrática. Orienta-se pela visão turva do gênero humano que passa a não se reconhecer no outro, nas necessidades expressas pela coletividade, mas, tão somente, em suas necessidades particulares. Nesse ponto de vista, segundo o autor, o distanciamento do humano das relações democráticas combativas, que exigem o humanismo ativo concretizado por meio de ações coletivas, propicia a fragilidade do humanismo e das formas de proteção do homem com relação ao poder de outro homem e deste para com as bases democráticas.

O complexo de crises, segundo Lukács, se combinados, tendem a promover solo fértil para a aspiração dos ideais fascistas e do totalitarismo, como ocorrido no período da Segunda Guerra Mundial. De acordo com o autor, o principal desafio da sociedade após a experiência mais concreta e exacerbada do fascismo ${ }^{13}$, 
é erradicar as raízes espirituais e morais desta forma de poder, que se encontra incorporada, inclusive, nos ditames que se dizem democráticos até na atualidade.

No contexto contemporâneo, a sociedade clama por prisões! Pede afoitamente justiça por meio do tratamento cruel e degradante de cidadãos ditos bandidos. Proclama insistentemente que bandido bom é bandido morto e diz que cada um tem as condições plenas de escolher não delinquir e andar na linha para não ser preso. Assim, como em um passe de mágica, estamos diante de uma sociedade que se aceita normal a partir das aberrações que ela mesma reproduz. Os ditos bandidos são os anormais que se esquivam das leis naturais dessa selva, e por isso, merecem um tratamento desumano. E dessa forma se banaliza o mal ${ }^{14}$, como dito por Hannah Arendt (2010), mata-se, extermina-se e deixa morrer, conforme detona a biopolítica ${ }^{15}$. O Estado efetiva e institucionaliza práticas de controle, repressão e violência de forma legitimada e faz da violação de direitos humanos sua diretriz.

\section{Considerações Finais}

Considerando o processo social como o processo de acúmulo de mudanças chegamos aqui, na contemporaneidade, com um histórico que agrega nossa colonização sanguinolenta e cruel em que nos foi imposta a nobre condição de explorados por nossas Colônias; a submissão e subsunção do povo brasileiro que acaba por reproduzir a lógica de repressão e enquadramento baseando-se em seus exploradores antigos e atuais; a absorção do racismo, do patriarcado e do conservadorismo, como conceitos estruturantes de nossa sociedade e que muito contribuíram e contribuem para o acirramento do processo de expropriação do homem/mulher negros, após libertos, enquanto trabalhadores inferiores; a introjeção da lógica capitalista de forma abrupta e desregulada gerando miséria e pobreza estruturais, que em sua maioria, afetaram e afetam o contingente populacional de negros e negras deste País. Acrescido a este conjunto, observamos o fortalecimento das ideias conservadores que visam desqualificar as políticas sociais e ações afirmativas em detrimento de políticas de repressão e controle cada vez mais robustas e dotadas de legitimidade social. Estamos diante de uma sociabilidade que impõe a repressão como regra e a liberdade como exceção. Construímos e fortalecemos o Estado penal como forma de obtenção de uma psseudossegurança social, classificando este modelo de Estado como necessário aos dias atuais.

Nesse momento Hannah Arendt é fonte irrefutável e inspiradora de nossas reflexões, uma vez que demonstra que quanto mais fraco, institucionalmente, é o Estado, quanto menos crédito perante a sociedade este possui, maior a chance de se tornar um Estado operacional crédulo na violência e no controle como formas de obtenção da legitimidade (ARENDT, 2010).

Dessa forma, o fortalecimento do modelo atual adotado pela política prisional brasileira, sustentada a partir da institucionalização das violações de direitos humanos, penas cruéis e degradantes aplicadas a um contingente social específico, executadas bem embaixo dos nossos narizes, torna-se medida fundamental ao Estado penal brasileiro contemporâneo.

Nesse sentido, argumentamos que a pena de prisão, nada mais é do que um subterfúgio, utilizado para a efetivação da pena de tortura, que na verdade é a sentença que se dá no momento em que se concebe a pena privativa de liberdade como algo a ser vivenciado por qualquer pessoa. E por que utilizamos esse argumento? Porque conhecendo o sistema prisional, consideramos que diante das condições que a pena de prisão impõe à pessoa, na atualidade, sobretudo brasileira, esta tem como intenção precípua a desumanização e a destituição de direitos dos classificados inimigos do Estado, para os quais a prisão serve como meio de vingança/castigo e estigmatização. Dessa forma, a pena privativa de liberdade se coloca em segundo plano, quando na verdade, o que se pretende é proceder com atos violadores de direitos de forma institucionalizada.

Contudo, ponderamos que a institucionalização de violações de direitos humanos nos espaços prisionais só é tarefa possível porque a conjuntura social e política brasileira possibilita a efetivação desses procedimentos como ordinários, imbuídos dos fragmentos de nossa história de autoritarismo e repressão. Assim, subsidiando tal institucionalização, um complexo de órgãos e instituições que acreditam e operacionalizam a pena privativa de liberdade a partir de premissas anti-humanistas em que se considera que "bandido bom é bandido morto" e que "direitos humanos é para humanos direitos", faz da política prisional a nossa principal política de controle dos pobres e da pobreza. 


\section{Referências}

AGUIRRE, C. Cárcere e Sociedade na América Latina (1800-1940). In: MAIA, C. N. et al. História das prisões no Brasil. Rio de Janeiro: Rocco, 2009

ALMEIDA, Sílvio Luiz de. O que é racismo estrutural? Belo Horizonte: Ed. Letramento, 2018.

ARAGÃO, I. R. Movimento da Lei e Ordem: sua relação com a lei dos crimes hediondos. Revista Âmbito Jurídico, São Paulo, jun. 2010. Disponível em: http://www.ambitojuridico.com.br/site/index.php?n_link=revista_artigos_leitura\&artigo_id=7938. Acesso em: 2 nov. 2018

ARENDT, H. Sobre a Violência. Rio de Janeiro: Civilização Brasileira, 2010.

BARBOSA, K. de S.; COELHO, N. M. M.S. A questão étnico-racial do sonho americano: o encarceramento dos pobres e pretos no Estado policial. Revista Brasileira de Segurança Pública, São Paulo, v. 11, n .1, p. 164-182, fev./mar. 2017.

BATISTA, N. et al. Direito Penal Brasileiro: primeiro volume: Teoria Geral do Direito Penal. Rio de Janeiro: Revan, 2003.

BAUMAN, Zygmunt. Modernidade e holocausto; tradução: Marcus Penchel. Rio de Janeiro: Zahar,1998.

BITENCOURT, C. R. Falência da pena de prisão: causas e alternativas. São Paulo: Saraiva, 2004.

BORGES, Juliana. O que é encarceramento em massa? São Paulo: Pólen Livros, 2018.

BOSCHETTI, I. 30 Anos do Congresso da Virada: Começaria Tudo Outra vez Se Preciso Fosse. Brasília: CFESS, 2009.

BRASIL. Levantamento Nacional de Informações Penitenciárias INFOPEN 2019. Brasília: Departamento Penitenciário Nacional, 2019. Disponível em: http://depen.gov.br/DEPEN/depen/sisdepen/infopen. Acesso em: 22 ago. 2019.

BRESSER-PEREIRA, Luiz Carlos. A crise da América Latina: Consenso de Washington ou crise fiscal?In: Pesquisa e Planejamento Econômico, 21 (1), abril, 1991, p.3-23. Disponível em: https://ppe.ipea.gov.br/. Acesso em 22 de novembro de 2018.

BRITO, Thammy Islamy Carlos. O Direito Penal do Inimigo de Gunther Jakobs. In: Jus.com.br. Disponível em: https://jus.com.br/ artigos/44783/o-direito-penal-do-inimigo-de-gunther-jakobs/1. Acesso em: 30 abr.2020. Publicado em nov/2015.

GENELHÚ, R.; SCHEERER, S. Manifesto para abolir as prisões. Rio de Janeiro: Revan, 2017.

JESCHECK, H. H. Tratado de Derecho penal. Barcelona: Bosch, 1981.

LUKÁCS, G. O Jovem Marx e outros escritos de filosofia. Rio de Janeiro: Ed. da UFRJ, 2007.

MENESES, T. B. de. Fundamentos do direito de punir. Revista dos Tribunais, São Paulo, ano 85, v. 727, maio 1996, p. 123-148.

MUÑOZ CONDE, F. La resocialización de delincuente. Análisis y crítica de um mito. CPC, Madrid, n. 7, 1979.

MAZZILLI NETO, R. Os caminhos do sistema penal, Rio de Janeiro: Revan, 2007.

MBEMBE, Achile. Achille Mbembe: "A era do humanismo está terminando", 2017. Disponível em: http://www.ihu.unisinos.br/78noticias/564255-achille-mbembe-a-era-do-humanismo-esta-terminando. Acesso em: 18 set. 2018

PIMENTA, V. M. Por trás das grades: o encarceramento em massa no Brasil. Rio de Janeiro: Revan, 2018.

ROSAL, M. C. D.; VIVES, T. Derecho Penal: Parte General. Spanish: Tirant Lo Blanch Paperback, 1999.

RUSCHE, G.; KIRCHHEIMER, O. Punição e Estrutura Social. Rio de Janeiro: Freitas Bastos, 2019.

SILVA, Enio Moraes. O Estado Democrático de Direito. In: Revista de Informação Legislativa, Brasília: Senado Federal, v.42, n.167, jul/set, 2005, p. $213-230$.

SOUZA, J. A Ralé Brasileira: Quem é e Como Vive. São Paulo: Contracorrente, 2017.

SPOSATI, A. Globalização da economia e processos de exclusão social. In: O significado socio-histórico das transformações da sociedade contemporânea. Capacitação em Serviço Social e Política Social. Módulo 01. Brasília, CEAD, 1999.

VITTO, R. de. "Presídios brasileiros são máquinas de moer gente", diz ex-diretor do Depen. O Povo, 08 jun. 2018. Disponível em: https://www.opovo.com.br/jornal/politica/2018/06/presidios-brasileiros-sao-maquinas-de-moer-gente-diz-ex-diretor-do.html. Acesso em: 14 jun. 2020.

XAVIER, B. G. O inimigo hipotético fundamental: quem és tu? Aproximações político-filosóficas. In: BATISTA, V. M.; CARVALHO, T. F. Política criminal e estado de exceção no Brasil: o direito penal do inimigo no capitalismo periférico. Rio de Janeiro: Revan, 2020, p. 21-76.

ZAFFARONI, R. E. O inimigo no direito penal. Rio de Janeiro: Revan, 2007.

\section{Notas}

Ralé brasileira: Classe formanda, fundamentalmente, por negros recém-libertos, mulatos, mestiços de demais vulneráveis sociais, que marca a modernização seletiva e desigual do contexto brasileiro (SOUZA, 2017). 
2 Welfare State: Durante a Segunda Guerra Mundial, mais precisamente em 1942, é formulado na Inglaterra o Plano Beveridge, que apresenta críticas ao modelo bismarckiano vigente até então, e propõe a instituição do welfare state. No sistema beveridgiano, os direitos têm caráter universal, destinados a todos os cidadãos incondicionalmente ou submetidos a condições de recursos, mas garantindo mínimos sociais a todos em condições de necessidade. O financiamento é proveniente dos impostos fiscais, e a gestão é pública, estatal. Os princípios fundamentais são a unificação institucional e uniformização dos benefícios (BOSCHETTI, 2009, p. 324).

3 As dez regras instituídas pelo Consenso de Washington são: 1) Disciplina fiscal - o Estado deve limitar os gastos à arrecadação, eliminando o déficit público; 2) Redução dos gastos públicos; 3) Reforma fiscal e tributária, na qual o governo deveria reformular seus sistemas de arrecadação de impostos e ampliar a base sobre a qual incide a carga tributária, com maior peso nos impostos indiretos; 4) Abertura comercial e econômica dos países, a fim de reduzir o protecionismo e proporcionar um maior investimento estrangeiro; 5) Taxa de câmbio de mercado competitivo; 6) Liberalização do comércio exterior; 7) Investimento estrangeiro direto, eliminando as restrições; 8) Privatização, com a venda das estatais; 9) Desregulamentação, com o afrouxamento das leis de controle do processo econômico e das relações trabalhistas; 10) Direito à propriedade intelectual (BRESSER-PEREIRA, 1991).

4 Termo utilizado para se diferenciar, de forma maniqueísta, questionável e com interesses da classe dominante, os cidadãos que merecem acessar e exercer seus direitos, dos demais, destituídos dos mesmos por não merecê-los ou não terem condições de exercê-los, de acordo com a maneira como a classe dominante observa como aceitável. O termo cidadão de bem diz muito de uma sociedade regida pela guerra entre classes, raças e gêneros e aponta o Estado como o responsável por prover mecanismos de segurança dos cidadãos de bem mesmo que estes estimulem práticas e ações de Estado que provoquem o extermínio, a humilhação e o não acesso aos direitos dos classificados inimigos da sociedade.

5 "O princípio da culpabilidade é o mais importante dos que derivam do Estado de Direito, porque sua violação implica o desconhecimento da essência do conceito de pessoa. Imputar um dano ou um perigo ao bem-jurídico sem a prévia constatação do vínculo subjetivo com o autor (ou impor uma pena baseada apenas na causação) equivale a rebaixar o autor à condição de coisa causante". (BATISTA et al., 2003, p. 245).

6 Considerando que as penas tinham características concretas, mas ainda se definiam no campo da abstração, a partir de intervenções divinas, por meio dos reis e do clero.

7 Consideramos, para fins destas constatações acerca do sistema prisional, outras pesquisas realizadas, a experiência profissional em que nos foi possível atuar diretamente no sistema prisional e no Sistema de Justiça, bem como nossa atuação enquanto militante nessa seara.

8 Termo cunhado por Borges (2018).

9 Parafraseando o ex-diretor do Departamento Penitenciário Nacional, Renato de Vitto, em sua palestra no $3^{\circ}$ Seminário Internacional de Segurança Pública, ocorrido em Fortaleza entre os dias 5 e 8 de junho de 2018. (VITTO, 2018).

10 "Não há momento histórico, no contexto de uma genealogia da cultura punitivista moderna, sem que tenha sido engendrada a definição específica de um determinado inimigo - em especial um "inimigo do Estado" (XAVIER, 2020, p. 21). Tivemos na história brasileira, como inimigos do Estado instituídos, primeiramente os comunistas e na contemporaneidade os traficantes, cuja desumanização, prevista no processo de instituição do inimigo, se mostram latentes no Brasil. "A teoria do Direito Penal do Inimigo teve sua origem descritiva exposta em uma palestra realizada pelo seu criador, o jurista e filósofo alemão Günther Jakobs, na Universidade de Bonn, na Alemanha, no ano de 1985, e era fruto de seu posicionamento crítico. Esta teoria foi influenciada sobremaneira pelos fundamentos do funcionalismo sistêmico, no qual Jakobs foi também o seu próprio criador e, desta forma, infere constar medidas de contenção àqueles indivíduos que não concordassem em respeitar as normas da sociedade, sendo atribuído um regramento penal próprio a ser aplicado a eles com base em sua não-inserção no status de pessoa" (BRITO, 2015, p. 1). Para Eugenio Raúl Zaffaroni (2007, p. 21), "a negação jurídica da condição de pessoa ao inimigo é uma característica do tratamento penal diferenciado que lhe é dado, porém não é a sua essência, ou seja, é uma consequência da individualização de um ser humano como inimigo".

11 Consideramos esse dado extremamente importante apesar de, aparentemente, não demonstrar ser imperativo. Contudo, precisamos salientar que, especificamente, com relação ao dado faixa etária, $10 \%$ dos apenados não foram contabilizados para aferição desse dado de perfil (BRASIL, 2019). Tal fato, acreditamos ser o motivo pelo qual o percentual não se mostra ainda mais robusto.

12 A partir dessa análise compreendemos, com base nas teorias descritas por Achille Mbembe (2017), a incompatibilidade da democracia liberal e a reprodução da lógica interna e necessária ao capitalismo financeiro, a incompatibilidade do humanismo para a sociabilidade capitalista.

13 Como bem lembra Bauman (1998, p. 22), "Qualquer instinto moral encontrado como conduta humana é socialmente produzido [...]". Diante de tal constatação precisamos nos questionar sobre o tipo de conduta humana que está sendo fomentada nas instituições do Estado Penal brasileiro, já que tais condutas remetem ao anti-humanismo, o mesmo implementado com voracidade contra negros, ciganos, imigrantes, deficientes e judeus, durante o Holocausto. 
14 A brilhante análise de Arendt levanta diversas questões em torno do poder e sua capacidade de incitação do mal, bem como enseja a conceituação em torno da Biopolítica, que se caracteriza pelo condicionamento de grandes massas, elevados contingentes populacionais, com finalidades determinadas.

15 O biopoder, como Foucault (2010 apud ALMEIDA, 2018).) denomina este modo de exercício do poder sobre a vida, é cada vez mais "disciplinar e regulamentador".

\section{Cibelle Dória da Cunha Bueno}

cibelledoria@gmail.com

Mestre em Serviço Social pela Universidade Estadual do Ceará (UECE)

\section{UECE}

Av. Dr. Silas Munguba, 1700, Campus do Itaperi

Fortaleza/CE, Brasil

CEP: 60714-903

\author{
Agradecimentos \\ Não se aplica. \\ Agência financiadora \\ Não se aplica. \\ Contribuições das autoras \\ Não se aplica.
}

\author{
Aprovação por Comitê de Ética e consentimento para \\ participação \\ Não se aplica. \\ Consentimento para publicação \\ Consentimento da autora. \\ Conflito de interesses \\ Não há conflito de interesses.
}

